\title{
Expression of Stress-Responsive Genes in Wheat (Triticum Aestivum) and its Progenitors Under Heat Stress
}

\author{
Mona M. Elseehy ${ }^{1}$
}

\begin{abstract}
Hexaploid wheat (Triticum aestivum, AABBDD) had developed from tetraploid and diploid progenitors with different genomic background. During evolution, changes in genome organization, gene expression, and genomic interactions occur. Real time PCR was employed to disclose changes in gene expression of three abiotic induced genes (DREB2, NAC6D, HSP17) in T. aestivum and four of its progenitors which had contributed in its development including Triticum turgidum (AABB), Triticum monococcum (AA), Aegilops spltoides (BB), and Aegilops taushii (DD) with different ploidy levels. Results showed that the three genes presented wide variations between $T$. aestivum and its progenitors as well as among its progenitors. Results suggested that $T$. aestivum could have inherited the high expression pattern of DREB2 from its progenitor $A$. speltoids, inherited its expression pattern of NAC6D form $T$. turgidum and/or A. taushii. The high expression pattern of HSP17 in $T$. aestivum could have been inherited from $A$. speltoides and/or $T$. turgidum. The obtained results support the notion that wheat progenitors have contributed in the gene expression profile of the hexaploid wheat. Results of this study will help detection of important genes in wheat progenitors that could be introduced into breeding programs for devolving new wheat varieties with desired characteristics.
\end{abstract}

Keywords: wheat, Triticum, Aegilops, DREB2, NAC6D, heat shock protein genes, wheat molecular evolution.

\section{INTRODUCTION}

Wheat (Triticum aestivum) is the main stable food crop for the world and is ranked third after maize and rice as source of food and feed (Elseehy and Alotaibi, 2020). It belongs to the Triticeae tribe that contains barley (Hordeum vulgare), rye (Secale cereale), and other wheat species including diploid and tetraploid wheat progenitors (El-Shehawi et al, 2012). It has been accepted that tribe Triticeae had diverged at the diploid level from common ancestor (Cox, 1998).

Hexaploid $T$. aestivum carrying the hexaploid genome AABBDD was developed 8,000 years ago as a result of Triticum turgidum (AABB) and Aegilops tauschii (DD) hybridization (McFadden and Sears 1946, Kimber and Sears, 1987, Friebe and Gill, 1996). It is strongly accepted that the A genome had descended from T. urartu (AA), that is very close relative of $T$. monococcum (AA). Also, it was suggested that Aegilops speltoides ( $\mathrm{S}$ genome) is the $\mathrm{B}$ genome donor for $\mathrm{T}$. aestivum (Dvorak and Zhang, 1990; Tsunewaki and Ogihara, 1983) and the cytoplasmic genome donor of polyploid wheats (Wang et al, 1997; Gaut, 1998).

Evolutionary processes from wild to domesticated types are slow and involve morphological, biochemical, and molecular changes in plants (Evans, 1981). Artificial selection during breeding programs to maximize the end product of grain yield and its quality leads to the loss of some useful alleles involved in biotic and abiotic stress resistance (Shimshi et al, 1982). This leads to variations among the domesticated species and its progenitors.

Several studies reported variations between the hexaploid wheat $\mathrm{T}$. aestivum and its progenitors. Tolerance to drought of wheat relatives was investigated using cell membrane stability, proline content, absisic acid (ABA), sugar mobilization, and osmotic regulation (Peleg et al, 2005; Reynolds et al, 2007; Kurahashi et al, 2009). Hexaploid wheat (T. aestivum, T. compactum) showed lower antioxidant activity than tetraploid wheat (T. dicoccum, T. dicoccoides and T. durum) and diploid wheat (T. monococcum) (Zhang and Kirkham, 1994). Progenitors of bread wheat (T. aestivum) A. taushii (DD) and $T$. dicoccoides (AABB) showed different antioxidant capacity in response to dehydration (Suneja et al, 2017). Similarly, two different accession (XJ002 and XJ098) of A. tauschii (hexaploid wheat progenitor) showed differential gene expression in response to drought that was estimated by transcriptome analysis (Zhao et al, 2020). In this study, 6969 DEGs (differentially expressed genes) related to drought resistance were detected. Drought tolerance was based on various factors including -linolenic acid, starch, sucrose metabolism and other pathways which was parallel to physiological changes correlated with drought resistance (Zhao et al, 2020).

It has been shown that ancient wheat varieties look similar to modern varieties, yet close investigation of both at the molecular level revealed that ancient and heritage wheat varieties differ from modern wheat varieties in their antioxidant and anti-inflammatory capacities. This also was observed at the health impact

DOI: 10.21608/asejaiqjsae.2021.154286

${ }^{1}$ Department of Genetics, Faculty of Agriculture,

University of Alexandria, 21545, Egypt

E-Mail:monaahmedma@yahoo.com.

Received February 05, 2021, Accepted March 07, 2021 
of older varieties which is attributed to their constituents that modulate inflammation and tissue permeability (Spisni et al, 2019). A. tauschii showed wide natural variations in drought resistance and sensitivity to ABA. Drought tolerant $A$. taushii were less sensitive to ABA. These variations were not completely observed in synthetic wheats resulted from crossing Langdon cultivar and A. taushii. On the other hand, synthetic varieties from more drought tolerant $A$. taushii showed higher drought tolerance and ABA sensitivity. The more drought tolerant varieties had the higher expression level it showed of three transcription factors (Kurahashi et al, 2009).

Improving wheat tolerance to high temperature through breeding is based on the use of genetic variations in wheat progenitors which depends on the characterization of high temperature tolerance related genes. Exposure to high temperature induced the expression of heat-induced genes in the thermotolerant Aegilops umbellulata (Rampino et al, 2020). This was investigated by differential display PCR. Also, sequence and structural of heat shock protein26 (HSP26) showed variations among various wheat progenitor as well as non-progenitor species. Variations included chromosome locations, copy number, single nucleotide polymorphism (SNPs), indels (Suneja et al, 2019). Variations revealed that positive selection during wheat evolution and the common ancestor of HSP26 among plants (Suneja et al, 2019).

High genetic variations in salt tolerance were observed in the SBLs (synthetic backcross lines) and their parents. This was observed at different growth stages. Some SBLs showed higher tolerance than their parents which represent a valuable source for salt tolerant alleles for breeding (Dadshani et al, 2019).

Heat shock protein (HSPs) genes are induced by high temperature to protect plants from deleterious effects of exposure to elevated temperature (Wahid et la 2007). HSPs are large protein family with various members including HSP90, HSP70, and HSP17 which are induced by high temperature (Basha et al, 2004, Alotaibi et al, 2020, Elseehy and Alotaibi, 2020). Many different transcription factors are induced by high temperature, such as DREB (Drought Responsive Element Binding) and NAC6D (Elseehy and Alotaibi, 2020, Alotaibi et al, 2020). DREB2 is induced by several abiotic stresses including drought, salinity, and elevated temperature (Du et al 2019). NAC genes are involved in various biological processes in plants, such as cell division, development, flowering, and response to abiotic stresses (Guerin et al, 2019; Uauy et al, 2006; Nakashima et al, 2012)

The focus of this study was to investigate gene expression level of two abiotic responsive transcription factors and one heat shock protein gene to disclose the possible changes in gene expression in T. aestivum and its progenitors. This will help in understanding how gene expression changes during evolution and detect novel useful genes in progenitors for developing new wheat varieties by breeding programs.

\section{MATERIAL AND METHODS}

\section{Plant growth and treatments}

Wheat (T. aestivum) and 4 wheat progenitors (Table 1) were utilized in the current study. Wheat seeds were sterilized using $1 \%$ sodium hypochlorite for $20 \mathrm{~min}$. Seeds were rinsed 3 times in distilled water, and the sterilized seeds were soaked in overnight. The imbibed seeds were germinated in plastic containers on $1 \%$ agar water; 2 containers for each wheat species. Germinated seeds were kept in the dark for 7 days at normal temperature. One container (about 100 plantlets) of each wheat lines was treated with high temperature at $40^{\circ} \mathrm{C}$ for $1 \mathrm{~h}$ (Speakman and Krueger 1983), while the other containers were kept at normal temperature. Directly after high temperature exposure, plantlets were collected and freeze-dried (lyophilized) at $-57^{\circ} \mathrm{C}$ for 48 h. Samples were ground in a coffee grinder and stored at $-20^{\circ} \mathrm{C}$ or used directly for total RNA isolation.

Table 1. Triticum and Aegilops species that were used in this study

\begin{tabular}{llll}
\hline \multicolumn{1}{c}{ Species } & \multicolumn{1}{c}{ Description } & Ploidy level & \\
\hline Triticum aestivum $(\mathrm{Ta})$ & Hexaploid wheat & AABBDD & \\
Triticum turgidum $(\mathrm{Ttu})$ & wheat progenitor & AABB & S genome = B genome \\
Triticum monococcum monocuccom $(\mathrm{Tm})$ & wheat progenitor & AA & Source of A genome \\
Aegilops speltoides $($ Asp $)$ & wheat progenitor & SS & S genome = B genome \\
Aegilops taushii $(\mathrm{At})$ & wheat progenitor & DD & Source of D genome \\
\hline
\end{tabular}


Table 2. Nucleotide sequence and information of primers used in the current study

\begin{tabular}{|c|c|c|c|c|c|}
\hline Gene & Primer & Nucleotide sequence 5 , to 3 ' & $\mathbf{T m}$ & Accession \# & PCR product, bp \\
\hline & TADREB2m-1F & GTTCCCCACTGCTGAGGAT & 59 & \multirow{2}{*}{ HQ171443.1 } & \multirow{2}{*}{480} \\
\hline DREB2 & TADREB2m-1R & GTGACCGGCTCAACTTCAAT & 58 & & \\
\hline & TAHSP17m-2F & GAGAAGGAGGACGCCAAGTA & 60 & \multirow{2}{*}{ JN572711.1 } & \multirow{2}{*}{274} \\
\hline HSP17 & TAHSP17m-2R & ACCAAAAGACAGACAGACCATC & 60 & & \\
\hline & TANAC6Dm-2F & GAGCTGGTGACACACTACCTCT & 63 & \multirow{2}{*}{ FN396831.1 } & \multirow{2}{*}{324} \\
\hline NAC6D & TANAC6Dm-2R & CATGATCCAGTTGGTCTTCTC & 59 & & \\
\hline & TATub-2F & AGTGTCCTGTCCACCCACTC & 62 & \multirow{2}{*}{ U76558.1 } & \multirow{2}{*}{244} \\
\hline Tubulin & TATub-2R & TGAAGTGGATCCTCGGGTAG & 60 & & \\
\hline
\end{tabular}

\section{Primers}

Specific primers were designed based on the respective gene accession from the gene bank. Table (2) summarizes the nucleotide sequence and primer information used in current study.

\section{Isolation of RNA}

RNA was isolated from ground shoot powder using QIAzol reagent (Qiagen, Hilden, Germany) (Elseehy and El-Shehawi 2020). One $\mathrm{mL}$ of QIAzol was transferred to $1.5 \mathrm{~mL}$ microfuge tube and $5 \mathrm{mg}$ of lyophilized tissue was added and mixed thoroughly by vortexing. The mixture was kept at room temperature (RT) for $5 \mathrm{~min}$. Cholorofom, $0.2 \mathrm{~mL}$, was added and mixed thoroughly, and then incubated at RT for $2 \mathrm{~min}$. The mixture was centrifuged at $4^{\circ} \mathrm{C}$ for $16 \mathrm{~min}$ at 12000 $\mathrm{xg}$. The supernatant was transferred to new tube. RNA was precipitated by the addition of one volume isopropanol and kept at RT for $15 \mathrm{~min}$. The RNA pellet was recovered by centrifugation $12000 \mathrm{xg}$ for $15 \mathrm{~min}$ at $4^{\circ} \mathrm{C}$. The obtained RNA was rinsed in $0.5 \mathrm{~mL}$ of $70 \%$ ethanol, and air-dried. The final RNA pellet was dissolved in DEPC-treated H2O. Quality and concentration of RNA were measured by the UV absorbance at $260 \mathrm{~nm}$ and the ration of A260/A280 respectively.

\section{Real Time PCR (qPCR)}

First strand synthesis of complementary DNA, cDNA, was carried out with the use of ImProm-II reverse transcriptase kit (Promega, Wisconsin, USA). The reaction was done in $20 \mu \mathrm{L}$ total volume of $1 \mathrm{X}$ ImProm-II reaction buffer. Each reaction included $2 \mu \mathrm{g}$ of total RNA, $0.5 \mu \mathrm{g}$ of random hexmer, $8 \mathrm{mM} \mathrm{MgCl} 2$, $0.5 \mathrm{mM}$ of dNTPs, and $1 \mu \mathrm{L}$ ImProm-II reverse transcriptase. Real time PCR reaction, $20 \mu \mathrm{L}$, included 1X GoTaq qPCR master mix (Promega, Wisconsin, USA), $250 \mathrm{nM}$ of forward and reverse primer (Table 2), $1 \mu \mathrm{L}$ of cDNA and was conducted in the C1000 Thermal Cycler (BioRad, California, USA). DNA amplicon was amplified under the following PCR conditions; $95^{\circ} \mathrm{C}$ for $3 \mathrm{~min}, 36$ cycles of $95^{\circ} \mathrm{C}$ for $20 \mathrm{~s}$,
$60{ }^{\circ} \mathrm{C}$ for $1 \mathrm{~min}$. The gene expression level of targeted genes (DREB2, NAG6D, HSP17) was normalized to the expression level of actin and was estimated by the $2^{-\Delta \Delta \mathrm{Ct}}$ method (Livak and Schmittgen 2001, Shukry et al 2020). Real time PCR data were analyzed using SPSS program (13.3 versions) and Duncan multiple range test (Heinisch, 1962) was applied to separate the means $(P \leq$ $0.05)$. Data are represented as means $\pm \operatorname{SE}(n=3)$.

\section{RESULTS AND DISCUSSION}

\section{Results}

The impact of high temperature on the expression of two stress-induced transcription factors (DREB2, NAC6D) and one heat shock protein gene (HSP17) was investigated in the current study. Gene expression was estimated using real time PCR utilizing the cDNA generated from RNA as template. Five wheat species were used representing the three genomes $\mathrm{AA}, \mathrm{BB}$, and DD in various genomic contexts. The hexploid wheat $T$. aestivum has the three genomes (AABBDD), $T$. turgidum has genomes $\mathrm{AA}$ and $\mathrm{BB}, T$. monococcum has genome AA, A. speltoides has genome SS which is similar to genome $\mathrm{BB}$, and A. taushii has genome DD. Estimation of gene expression of stress responsive genes in hexaploid wheat in comparison to different genomic background of its progenitor can disclose how gene expression changes among T. aestivum and its progenitors as well as the interaction of various genomes during evolution.

Investigation of DREB2 expression showed differences among the five wheat species in response to high temperature for 1 hour. A. speltoides was the highest responder to high temperature with DREB2 expression of 4.9 fold compared to normal condition. Also, T. aestivum showed 4.5 fold of DREB2 expression compared to the control (Fig.1). The other three species $T$. turgidum, $T$. monococcum, and $A$. taushii showed lower response to high temperature with fold change 2.8, 2.4, and 2.3 compared to the normal conditions consecutively (Fig. 1). For each wheat 
species the DREB2 was significantly induced by high temperature compared to normal condition. Tm and At did not show significant induction of DREB2, whereas Ttu was induced significantly compared to Tm and At. Asp and Ta were significantly induced compared to other species (Fig.1). Based on their response to high temperature, the five species can be ranked as Asp $>\mathrm{Ta}>\mathrm{Ttu}>\mathrm{Tm}>\mathrm{AT}$.

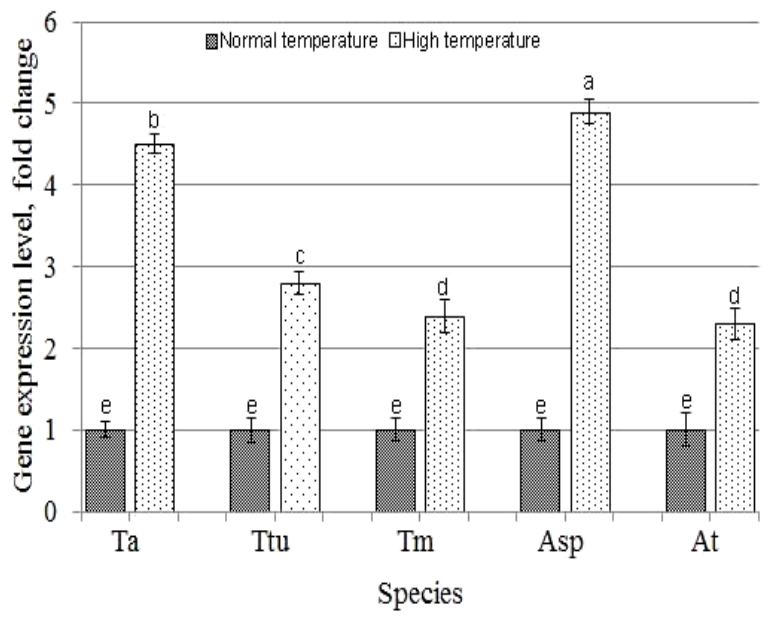

Fig. 1. Real time PCR of DREB2 transcription factor in the five wheat species used in this study. Ta: T. aestivum, Ttu: T. turgidum, Tm: T. monococcum, Asp: A. speltoides, At: A. tauschii. Different letters means significant different $(\mathbf{p} \leq \mathbf{0 . 0 5})$

Expression of NAC6D was widely differed among the five wheat species investigated in this study. All five species had significant level of NAC6D induction in response to high temperature compared to normal condition (Fig.2). Different species differed in their response to high temperature. T. aestivum responded highest to high temperature in NAC6D expression with 5.1 fold change increase. T. turgidum and A. taushii had very close level of expression of NAC6D at 4.8 and 4.7 fold respectively. The top three species (Ta, Ttu, At) showed insignificant variations in NAC6D expression in response to high temperature. T. monococcum and A. speltoides showed close level of expression with 2.9 and 2.6 fold changes respectively. T. monococcum and A. speltoides did not represent significant difference in NAC6D expression (Fig. 2). The five species can be ranked as $\mathrm{Ta}>\mathrm{Ttu}>\mathrm{AT}>\mathrm{Tm}>\mathrm{Asp}$ based on their expression level induced by high temperature.

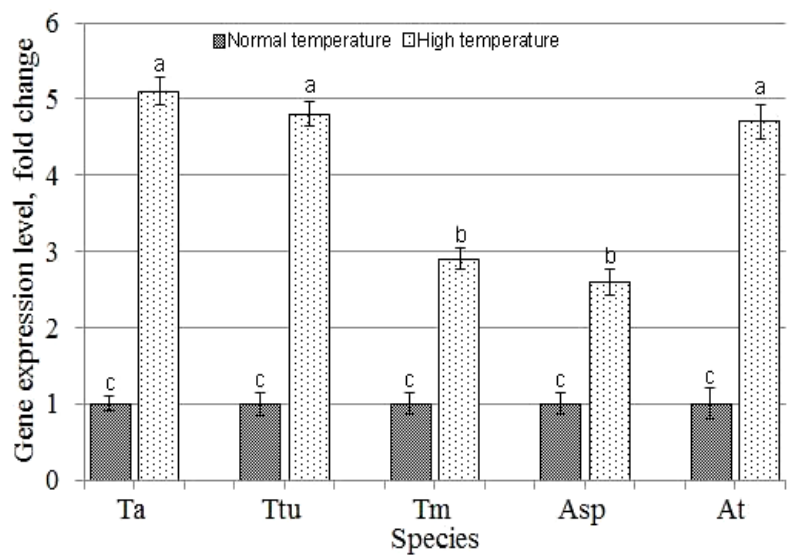

Fig. 2. Real time PCR of NAC6D transcription factor in the five wheat species used in this study. Ta: T. aestivum, Ttu: T. turgidum, Tm: T. monococcum, Asp: A. speltoides, At: A. tauschii. Different letters means significant different $(\mathbf{p} \leq \mathbf{0 . 0 5})$

Under high temperature, wheat species presented significant upregulation of HSP17 gene expression compared to its expression under normal condition. A. speltoides showed the highest level of HSP17 induction in response to high temperature with 4.6 folds change increase (Fig.3). T. aestivum and T. turgidum presented 4.3 and 4.1 fold of induction of HSP17 gene with insignificant difference. T. monococcum and A. taushii showed 2.3 and 2 fold change of induction with insignificant differences (Fig.3). The five species can be ranked as Asp $>\mathrm{Ta}>\mathrm{Ttu}>\mathrm{Tm}>\mathrm{AT}$ based on their expression level induced by high temperature.

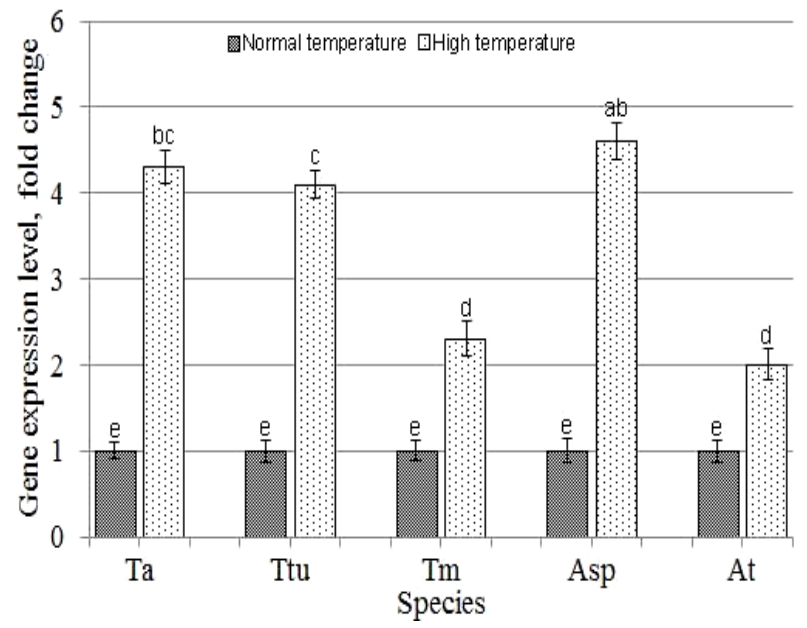

Fig. 3. Real time PCR of HSP17 transcription factor in the five wheat species used in this study. Ta: $T$. aestivum, Ttu: T. turgidum, Tm: T. monococcum, Asp: A. speltoides, At: A. tauschii. Different letters means significant different $(p \leq 0.05)$ 


\section{Discussion}

The expression pattern of 3 genes ( 2 abiotic stress response transcription factors, 1 HSP gene) was employed to investigate the changes in expression pattern through evolution. Five Triticum and Aegilops species representing different ploidy levels $(2 n-6 n)$ as well as different evolutionary stages of the heaxaploid wheat (T. aestivum) were used. The three used genes presented significant variations among the five Triticum and Aegilops species in response to high temperature.

A. tauschii (DD) had contributed the DD genome to T. aestivum (AABBDD) and T. turgidum (AABB) has contributed the AA and $\mathrm{BB}$ genomes (McFadden and Sears, 1946; Kimber and Sears, 1987; Friebe and Gill, 1996). The AA genome was derived from $T$. monococcum (AA) which is close relative to $\mathrm{T}$. urartu (AA), whereas the BB genome was derived from $\mathrm{A}$. speltoids and contributed to $\mathrm{T}$. aestivum through $\mathrm{T}$. turgidum (Sasanuma et al, 1996).

DREB2 showed significant induction in $\mathrm{T}$. aestivum compared to the other two Triticum species ( $\mathrm{T}$. turgidum, T. monococcum) although $\mathrm{T}$. monococcum is the AA genome donor to $\mathrm{T}$. aestivum through $\mathrm{T}$. turgidum and T. turgidum (AADD). A. speltoides had higher level of DREB2 compared to the other Aegilops species A. taushii (DD). It seems T. aestivum inherited the expression pattern of DREB2 from A. speltoides through its $\mathrm{BB}$ genome not from AA from $\mathrm{T}$. monococcum or DD genome from A. taushii. Interestingly, T. turgidum had lower level of DREB2 expression although it supposed to inherit the BB genome form the A. speltoides. This could be explained by DREB2 was suppressed in T. turgidum after it was combined with AA genome from $\mathrm{T}$. monococcum, while domestication of $\mathrm{T}$. aestivum led to the induction of DREB2 in the new genomic context AABBDD.

This explanation agrees with the accepted notion that during evolution from wild species to domesticated ones through biochemical and loss of alleles and finally leading to variations among the domesticated species and their progenitors (Evans, 1981, Shimshi et al, 1982). For example, antioxidant activity of hexaploid wheat (T. aestivum and $\mathrm{T}$. compactum) was decreased in compared to tetraploid wheat ( $\mathrm{T}$. dicoccum, $\mathrm{T}$. dicoccoides and $\mathrm{T}$. durum) as well as the $\mathrm{T}$. monococcum (diploid wheat) indicating a decrease of antioxidant capacity through evolution (Zhang and Kirkham, 1994). Also, progenitors of T. aestivum (A. tauschii (DD) and $\mathrm{T}$. dicoccoides (AABB)) differed in their antioxidant activity after their exposure to drought (Suneja et al, 2017). In addition, upon exposure to drought, two accessions of A. tauschii (DD genome contributor) represented difference in gene expression of 6969 genes related to drought tolerance which was parallel to physiological changes correlated with drought resistance (Zhao et al, 2020). Interestingly, ancient and modern wheat varieties revealed various molecular differences including antioxidant and antiinflammatory capacities. Also, they differ in their health benefits attributed to modulation of inflammation and tissue permeability (Spisni et al, 2019). Synthetic backcross lines (SBLs) and their parents showed high genetic variations in salt tolerance. Some SBLs showed higher tolerance than their parents which represent a valuable source for salt tolerance alleles for breeding (Dadshani et al, 2019).

Wide natural variations were observed in A. taushii regarding drought tolerance and $\mathrm{ABA}$ sensitivity compared to synthetic wheat varieties produced by crossing Langdon cultivar and A. taushii. On the contrary, varieties produced by drought tolerant A. taushii were more drought-tolerant and more sensitive to $\mathrm{ABA}$. It is noteworthy that, the more drought tolerant varieties had higher expression level of three transcription factors (Kurahashi et al, 2009). Aegilops umbellulata showed induction of high temperatureinduced genes after exposure to elevated temperature (Rampino et al, 2020).

Variations of heat shock protein26 (HSP26) structure were detected among wheat progenitors species including chromosome locations, copy number, single nucleotide polymorphism (SNPs), indels (Suneja et al, 2019). Based on the detected Variations, it was suggested that positive selection had occurred during wheat evolution common ancestor of HSP26 among plants (Suneja et al, 2019).

The induction of the three studies genes agrees with their induction in previous reports. Heat shock protein (HSPs) genes are induced by high temperature to protect plants from deleterious effects of exposure to elevated temperature (Wahid et al, 2007, Alotaibi et al, 2020). HSP17 was induced by high temperature in Egyptian wheat varieties (Elseehy and Alotaibi, 2020) and its induction was regulated by methylation of its promoter (Alotaibi et al, 2020). DREB2 was induced by high temperature and several abiotic stresses including salinity and drought ( $\mathrm{Du}$ et al, 2018, Elseehy and Alotaibi 2020). NAC6D was induced by high temperature in Egyptian wheat varieties (Elseehy and Alotaibi, 2020). The hexaploid wheat (T. aestivum) and its tetraploid as well as diploid progenitors showed variations in the organization and expression of the mitochondrial gene orf 256 which is associated with cytoplasmic male sterility (Hedgcoth et al 2002, ElShehawi et al 2003, El-Shehawi et al, 2012).

From the obtained results, there was a change in gene expression response to high temperature during wheat evolution. This was indicated in differences in 
gene expression level among hexaploid wheat ( $\mathrm{T}$ aestivum) and its tetraploid and diploid progenitors.

\section{REFERENCES}

Alotaibi, S.S., A.M. El-Shehawi and M.M. Elseehy. 2020. Heat Shock Proteins Expression Is Regulated by Promoter CpG Methylation/demethylation under Heat Stress in Wheat Varieties. Pak. J. Biol. Sci. 23: 1310-1320.

Basha, E., G.J.Lee, B.Demeler and E.Vierling. 2004. Chaperone activity of cytosolic small heat shock proteins from wheat. Eur. J. Biochem. 271:1426-1436.

Cox, T.S. 1998. Deepening the wheat gene pool. J. Crop Prod. 1, doi:10.1300/J144v01n01_01.

Dadshani, S., R.C.Sharma, M.Baum, F.C.Ogbonnaya, J.Léon and A.Ballvora. 2019. Multi-dimensional evaluation of response to salt stress in wheat. PLoS One. 14(9):e0222659.

Du, X., W.Li, L.Sheng, Y.Deng, Y.Wang, W.Zhang, K.Yu, J.Jiang, W.Fang, Z.Guan, F.Chen and S. Chen. 2018. Over-expression of chrysanthemum CmDREB6 enhanced tolerance of chrysanthemum to heat stress. BMC Plant Biology. 18 (1):178.

Dvorak, J. and H.B. Zhang. 1990. Variation in repeated nucleotide sequences sheds light on the phylogeny of the wheat B and G genomes. Proc. Natl. Acad. Sci. USA. 87:9640-9644.

Elseehy, M.M. and S. Alotaibi. 2020. Expression of heat shock genes in Egyptian wheat (Triticum aestivum) varieties in response to high temperature. Res. J. Biotech. 15(2):96-102.

Elseehy, M.M. and A.M. El-Shehawi. 2020. Methylation of Exogenous Promoters Regulates Soybean Isoflavone Synthase (GmIFS) Transgene in T0 Transgenic Wheat (Triticum aestivum), Cytology and Genetics. 54(3):271282.

El-shehawi, A.M., M.M. Elseehy and C.Hedgcoth. 2003. orf256-coxI RNA binds to wheat mitochondrial proteins. Arab J. Biotech. 6: 29-38.

El-Shehawi, A.M., A.I.Fahmi, S.M.Sayed and M.M. Elseehy. 2012. Genetic Fingerprinting of Wheat and Its Progenitors by Mitochondrial Gene orf256. Biomolecules. 2: 228-239.

Evans, L.T. 1981. Yield improvement in wheat: empirical or analytical? In: Evans LT, Peacock WJ (eds) Wheat science-today and tomorrow. Cambridge University Press, Cambridge. 203-222.

Friebe, B. and B.S. Gill. 1996. Chromosome Banding and Genome Analysis in Diploid and Cultivated Polyploid Wheats. In Methods of Genome Analysis in Plants; CRC Press: Boca Raton, FL, USA. 39-60.

Gaut, B.S. 1998. Molecular clocks and nucleotide substitution rates in higher plants. Evol. Biol. 30: 93-120.

Guerin, C., J.Roche, V.Allard, C.Ravel, S.Mouzeyar and M.F. Bouzidi. 2019. Genome-wide analysis, expansion and expression of the NAC family under drought and heat stresses in bread wheat (T. aestivum L.). PLoS ONE, 14 (3): $\mathrm{e} 0213390$.
Hedgcoth, C., A.M.El-shehawi, P.Wei, M. Clarkson and D. Tamalis. 2002. A chimeric open reading frame associated with cytoplasmic male sterility in alloplasmic wheat with Triticum timopheevi mitochondria is present in several Triticum and Aegilops species, barley and rye. Curr Genet. 41: 357-365.

Heinisch, O. 1962. Steel, R. G. D., and J. H. Torrie: Principles and Procedures of Statistics. (With special Reference to the Biological Sciences) McGraw-Hill Book Company, New York, Toronto, London 1960, 481 S., 15 Abb.; 81 s 6 d. Biometrische Zeitschrift. 4: 207-208.

Kimber, G. and E.R. Sears. 1987. Evolution in the Genus Triticum and the Origin of Cultivated Wheat. In Wheat and Wheat Improvement; Heyne, E.G., Ed.; American Society of Agronomy: Madison, WI, USA. 154-164.

Kurahashi, Y., A.Terashima and S.Takumi. 2009. Variation in dehydration tolerance, ABA sensitivity and related gene expression patterns in D-genome progenitor and synthetic hexaploid wheat lines. Intl J Mol Sci. 10:2733-2751.

Livak, K.J., and T.D. Schmittgen. 2001. Analysis of relative gene expression data using real-time quantitative PCR and the 2(-Delta Delta C(T)) Method. Methods. 25(4):402-8.

McFadden, E.S. and E.R. Sears. 1946. The origin of Triticum speltoides and its free-threshing hexaploid relatives. J. Hered. 37: 81-89.

Nakashima, K., H. Takasaki, J. Mizoi, K. Shinozaki and K. Yamaguchi-Shinozaki. 2012. NAC transcription factors in plant abiotic stress responses. Biochim Biophys Acta. 1819 (2):97-103.

Peleg, Z., T.Fahima, S.Abbo, T.Krugman, E.Nevo, D.Yakir and Y. Saranga. 2005. Genetic diversity for drought resistance in wild emmer wheat and its ecogeographical associations. Plant Cell Environ. 28:176-191.

Rampino, P., M.De Pascali, C.Perrotta and M. Gullì. 2020. New gene functions are involved in the thermotolerance of the wild wheat relative Aegilops umbellulata. Plant Physiol Biochem. 156:115-124.

Reynolds, M., F.Dreccer and R.Trethowan. 2007. Drought adaptive traits derived from wheat wild relatives and land races. J Exp Bot. 58:177-186.

Sasanuma, T., N.T. Miyashita and K. Tsunewaki. 1996. Wheat phylogeny determined by RFLP analysis of nuclear DNA. 3. Intra- and interspecific variations of five Aegilops Sitopsis species. Theor. Appl. Genet. 92:928-934.

Shimshi, D., M.L. Mayoral and D.Atsmon. 1982. Responses to water stress in wheat and related wild species. Crop Sci. 22:123-128.

Shukry, M., A.M. El-Shehawi, W.M. El-Kholy, R.A.Elsisy, H.S.Hamoda, H.G.Tohamy, M.M.Abumandour and F.A. Farrag. 2020. Ameliorative Effect of Graviola (Annona muricata) on Mono Sodium Glutamate-Induced Hepatic Injury in Rats: Antioxidant, Apoptotic, Anti-inflammatory, Lipogenesis Markers, and Histopathological Studies. Animals. 10:1996.

Speakman, J.B. and W. Krueger. 1983. A comparison of methods to surface sterilize wheat seeds. Trans. Br. Mycol. Soc. 80:374-376. 
Spisni, E., V.Imbesi, E.Giovanardi, G.Petrocelli, P.Alvisi and M.C.Valerii. 2019. Differential Physiological Responses Elicited by Ancient and Heritage Wheat Cultivars Compared to Modern Ones. Nutrients. 11(12):2879.

Suneja, Y., A.K.Gupta and N.S. Bains. 2017. Bread wheat progenitors: Aegilops tauschii (DD genome) and Triticum dicoccoides (AABB genome) reveal differential antioxidative response under water stress. Physiol Mol Biol Plants. 23(1):99-114.

Suneja, Y., A.K.Gupta, P.Chhuneja and N.S. Bains. 2019. Molecular evolution and structural variations in nuclear encoded chloroplast localized heat shock protein 26 (sHSP26) from genetically diverse wheat species. Comput Biol Chem. 83:107144.

Tsunewaki, K. and Y. Ogihara. 1983. The Molecular Basis of Genetic Diversity among Cytoplasms of Triticum and Aegilops Species. II. on the Origin of Polyploid Wheat Cytoplasms as Suggested by Chloroplast DNA Restriction Fragment Patterns. Genetics. 104:155-171.

Uauy, C., A.Distelfeld, T.Fahima, A.Blechl and J.Dubcovsky. 2006. A NAC Gene Regulating Senescence Improves
Grain Protein, Zinc, and Iron Content in Wheat. Sci. 314:1298-1301.

Wahid, A., S.Gelani, M.Ashraf. and M.R. Foolad. 2007. Heat tolerance in plants: An overview. Environ Exp Bot. 61(3):199-223.

Wang, G.Z., N.T. Miyashita and K. Tsunewaki. 1997. Plasmon analyses of Triticum (wheat) and Aegilops: PCRsingle-strand conformational polymorphism (PCR-SSCP) analyses of organellar DNAs. Proc. Natl. Acad. Sci. USA. 94:14570-14577.

Zhang, J. and M.B. Kirkham. 1994. Drought stress induced changes in activities of superoxide dismutase, catalase and peroxidase in wheat species. Plant Cell Physiol. 35:785791.

Zhao, X., S.Bai, L. Li, X.Han, J.Li, Y.Zhu, Y.Fang, D.Zhang and S. Li. 2020. Comparative Transcriptome Analysis of Two Aegilops tauschii with Contrasting Drought Tolerance by RNA-Seq. Int J Mol Sci. 21(10):3595.

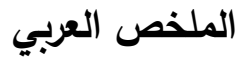 \\ التعبير الجيني للجينات المستحثة بالإجهاد في القمح (Triticum aestivum) وأصوله تحت ظروف \\ الإجهاد الحراري

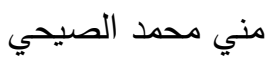

الدراسة أن القدح السداسي aestivum قد ورث التعبير

A. الجيني العالي للجين DREB2 من الأصل الوراثي speltoides NAC6D أو الأصل الوراثي T. turgidum من الأصل الوراثي

HSP17 A. taushii T. الو الأصل الوراثي A. speltoides الوراثل turgidum وأكدت نتائج الدراسة أن الأصول الوراثية للقصح السداسي ساهمت في نموذج التعبير الجيني للثلاثة جينات تحت الدراسة.

نتائج الدراسة سوف تساهم في تحديد عديد من الجينات ذات الأهمية الإقتصادية في الأصول الوراثية للقمح والتي يمكن أن تستخدم في برامج التربية لإنتاج أصناف جديدة ذات خصائص مرغوبة.
تطور القمح السداسي (Triticum aestivum) والذي يحمل

الجينوم AABBDD من أصول القهح الرباعية والثنائية والتي تحمل جينوم مختلف، وخلال التطور تحدث تغيرات في إنتظام الجينوم والتعبير الجيني والتقاعل الجينومي بين Real time المصادر الجينومية المختلفة. تم إستخدام تقنية وتئية لدراسة التغير في تعبير ثلاثة جينات مستحثه PCR

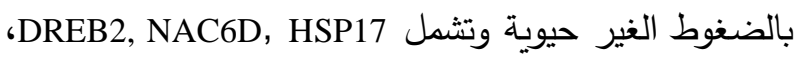
وذلك في القهح السداسي T. aestivum وأربعة أنواع من Triticum turgidum الأصول التي شاركت في تطوره وتشمل (AABB), Triticum monococcum (AA), Aegilops spltoides (BB), Aegilops taushii (DD) جينومات مختلفة ومستوي تضاعف مختلف. أظهرت نتائج الدراسة اختلافات معنوية واسعة في تعبير T. الجينات الثلاثة التي تم دراستها بين القهح السداسي aestivum وأصوله الوراثية الأربعة تحت الدراسة، وتثير نتائج 